\title{
Como falava a tipografia do cinema mudo?
}

\author{
Roberto Tietzmann (tietz@pucrs.br)
}

\section{Introdução}

Definir o cinema dos anos anteriores ao filme "O Cantor de Jazz" (1928) como exclusivamente mudo revela uma simplificação das diversas estratégias comunicacionais que os discursos cinematográficos encontravam para iluminar as telas e envolver seus espectadores.

Desde seus primeiros momentos o cinema apresentou elementos gráficos (tipografia, diagramas, sinais, etc.) somados às imagens captadas pelas câmeras. Tal mescla era capaz de sugerir significados mais complexos do que apenas as imagens filmadas seriam capazes de representar. Neste artigo buscamos descrever algumas das maneiras que o cinema anterior ao som sincronizado encontrou para escrever suas mensagens através da soma de elementos gráficos e cinematográficos.

2. As diversas relações entre público e filme na aurora do cinema

Os registros mais imediatos do final do século XIX, desde locomotivas até cenas urbanas, de paisagens incríveis até cinejornais, representavam o registro visual do efêmero em um mundo conhecido, cujos sons eram reconhecíveis e facilmente completados na leitura de suas platéias. A mediação da imagem cinematográfica sem som sincronizado estava mais próxima, portanto, daquela realizada pela fotografia desde seu surgimento.

Mesmo no século XXI, a maioria das imagens fotográficas continua sendo captada sem som sincronizado com a imagem. Isto não retira do espectador a capacidade de atribuir em sua leitura um som às imagens registradas nem tampouco o obriga a esquecer da voz de amigos e familiares que sorriem estáticos. Meios técnicos foram construídos para 
superar tal ausência de som na fotografia digital (onde a maioria das câmeras pode gravar segundos de som junto de cada arquivo digital de imagem, servindo como uma legenda oral), mas a maioria dos espectadores não sente necessidade de tais possibilidades nem os utiliza.

Musser (1994, p.2) afirma que existiam três modos de recepção nos filmes dos primeiros dez anos do cinema.. A primeira delas era baseada no reconhecimento imediato das situações mostradas na tela, com o mínimo de apoio de uma legenda ou cartão de título inicial. Muito das informações necessárias para entender a obra, portanto, não estavam na tela, mas no contexto cultural do espectador que a lia. A familiaridade era fruto de um delicado jogo de denotação e conotação e interpretação entre o filme e seu público.

Outro modo, segundo Musser (1994, p.2), dependia de um acréscimo de elementos que transcendiam a tela. Requeria um envolvimento maior do exibidor em investir e proporcionar extras à imagem filmada. Tendo em vista a compreensão do filme e uma experiência mais completa para o espectador, o empresário poderia acrescentar uma narração à imagem, música e até vozes e efeitos sonoros realizados ao vivo, em uma curiosa hibridização entre cinema e teatro.

Carrière (1994, p.13) relata que os filmes projetados na Espanha em torno de 1910 eram acompanhados pela figura do explicador: um funcionário do cinema que ficava ao lado da tela com um bastão apontando os personagens e explicando o que eles estavam fazendo e o significado disto. A função de ancorar a conotação "correta” a partir dos signos apresentados no filme mostra a vocação do cinema para buscar a uniformidade de opiniões a respeito de seus filmes.

Segundo Musser (1994, p.2) o terceiro modo de organizar os elementos no filme apresentava histórias que deveriam ser compreendidas com o mínimo de elementos externos à obra. Neste caso, as formas de representar a história variavam bastante. De filmes "de truque” como os de Méliès no início de sua carreira ou filmes que se baseavam no encadeamento de ações e situações através do uso de cartões, as estratégias para a 
Revista da Associação Nacional dos

Programas de Pós-Graduação em Comunicação

\section{(e) compós}

www.compos.org. br

representação de histórias mais complexas era variada e dependia de um afastamento do mero registro realista e da estabilização de uma convenção narrativa ainda instável.

Entre as três formas de representação listadas por Musser (1994) um elemento comum que se apresenta é a incorporação da linguagem verbal gráfica na forma de tipografia em palavras e pequenas frases escritas aplicadas em cartões ou sobre as imagens. A construção de significados em relação entre as duas imagens se estruturou em diversas formas pautadas pelas necessidades de comunicação.

3. Legendas, créditos e outras interferências gráficas sobre o cinematográfico

A mescla de texto e imagens como maneira de construir uma mensagem não foi algo inventado pelo cinema. Cartuns satíricos com legendas eram freqüentes em publicações do século XIX (Fonseca, 1999), bem como as etapas da Via Crucis mostrando a paixão de Cristo acompanhadas de legendas sintéticas de suas cenas faziam parte da cultura cristã, dominante na Europa, há centenas de anos. Convenções gráficas a respeito da atribuição do tamanho maior da tipografia a temas mais importantes vão ainda mais longe (Twyman, 1982; Meggs, 1995), remontando ao Império Romano e até antes. De uma forma geral, a origem da articulação de imagem e texto se perde no tempo e foge de nosso objeto de estudo.

O que o cinema trouxe de novo, no entanto, foi a possibilidade de definir uma seqüência de cartões com texto e imagens captadas pela câmera cujo andamento e, portanto, a sugestão da ordem preferencial de leitura, fosse pré-definido por um autor através da montagem cinematográfica. O objetivo dos textos gráficos era elucidar incertezas e ambigüidades a partir das imagens apresentadas no filme. Tal conceito está em sintonia com o que Barthes define como ancoragem, segundo Fiske (1983): 
Revista da Associação Nacional dos

Programas de Pós-Graduação em Comunicação

\section{(e) compós}

www.compos.org. br

Um termo usado por Barthes para descrever o caminho principal pelo qual as palavras trabalham sobre as imagens visuais - usualmente propagandas ou fotojornalismo. Fotografias são potencialmente textos abertos e palavras são usadas para dirigir o leitor rumo a uma leitura preferencial da imagem. (FISKE, 1983, p.11)

Barthes escrevia suas considerações a respeito de fotojornalismo e publicidade, mas o conceito também se aplica ao cinema. Neste caso, a ambigüidade e a polissemia inerentes à imagem se cruzam com as diferentes necessidades artísticas, comunicacionais e comerciais de uma obra.

Por exemplo, é praticamente ininteligível entender a quem pertence uma imagem em movimento apenas observando poucos segundos dela. O acréscimo de uma logomarca à imagem ancora tal significado e sugere que tal imagem se insere em um meio onde tal marcação seja importante e um fator de distinção. Relações semelhantes podem ser encontradas na apresentação gráfica de títulos, textos de diálogos, de indicativos de passagem de tempo ou de pontos-chave da trama.

Nos primeiros anos do século XX, as necessidades de ancoragem presentes nos três modos de relação entre o filme e seu espectador sugeridos por Musser (1994), já haviam estruturados os cinco tipos de ligações tipográficas com o material filmado que existem até hoje: os créditos de abertura, os intertítulos de fala, os intertítulos narrativos, a tipografia endógena e os créditos finais.

- Os créditos de abertura iniciaram-se informando a quem o filme pertencia através de pequenos símbolos gráficos anexados ao cenário. $\mathrm{Na}$ aurora do cinema mudo também serviram, como afirma Musser (1994, p.2) para dar uma rápida pista do que se tratava o filme, depois tendo agregado depois mais informações e uma grande variedade na forma de sua apresentação. 
- Os intertítulos de fala pontuavam a pantomima com diálogos. Na verdade, os díalogos eram entendidos em síntese entre as ações das personagens e um resumo das afirmações. Dificilmente eles representavam um diálogo com todas as suas falas, uma vez que as interrupções seriam muito freqüentes e potencialmente desagradáveis para o espectador.

- Os intertítulos narrativos acrescentavam ao cinema informações que apenas a seqüência de imagens teria dificuldade de comunicar. Tais intertítulos nos lembram que estamos em "Londres, 1875” ou "Na Cidade que Nunca Dorme” ou ainda que estamos “Seis meses depois”. Em filmes como A Linha Geral (Sergei Eisenstein, 1929) esquemas gráficos aparecem em intertítulos para mostrar o progresso da agricultura soviética.

- A tipografia endógena são as palavras e textos gráficos que aparecem fazendo parte do cenário (nome de loja em fachada), figurino (escritos em camisetas, etiquetas), personagens (tatuagens) ou objetos de cena (cartas, bilhetes, telas em computador) e que, portanto, foram captados por uma câmera. No cinema mudo, em geral, eram apenas acessório para a imagem.

- Os créditos finais resumiam-se a pouco mais do que o "The End”, quando presentes. Apenas com o fortalecimento dos sindicatos e a quebra do monopólio dos grandes estúdios no mercado americano na década de 1960 os créditos finais passaram a listar de maneira extensa os envolvidos na realização da obra.

Cada uma destas cinco ligações entre imagens cinematográficas e elementos gráficos se definiu em convenções específicas que permitiam sua identificação e leitura com 
Revista da Associação Nacional dos

Programas de Pós-Graduação em Comunicação

\section{(e) compós}

www.compos.org.br

agilidade. Aprofundaremos este estudo em duas categorias específicas: os créditos de abertura e os cartões com diálogos, descrições ou narração.

4. Créditos de abertura : dizendo a quem o filme pertence

Desde a origem do cinema há algum tipo de crédito de autoria presente, sejam as pequenas placas colocadas no cenário identificando a empresa que produziu o filme (Toulet, 2000, p.77), os carimbos que Thomas Edison e Georges Méliès (Usai, 2000, encarte) colocavam entre os fotogramas identificando sua propriedade de maneira quase subliminar.

É importante observar, contudo, que este crédito freqüentemente se refere primeiro à autoria relacionada à pessoa jurídica responsável pelo filme, a empresa produtora e demais financiadores. Tal preocupação seminal entre todos os envolvidos com a nascente indústria demonstra que havia uma vertiginosa competição feita de medidas lícitas e ilícitas. Buscando a identificação dos autores para fins de responsabilidade perante uma ação judicial (Mannoni, 2003, p.320), logotipos das empresas eram mesclados no cenário:

Com um galo, uma águia, uma margarida, uma estrela preta ou iniciais dissimuladas nos cenários dos filmes, as primeiras produtoras tentam controlar uma indústria ainda sem leis. (TOULET, 2000, p.77)

No cartão de título para o filme “O Grande Roubo do Trem”, dirigido por Edwin Porter em 1903 para a empresa de Thomas Edison, a preocupação com a assinatura da produtora é exibida de maneira exemplar. Há simplesmente duas vezes no quadro a indicação que o filme possui um copyright de 1903, e também está duplicada a indicação de que Edison é o produtor. A redundância da informação busca garantir uma proteção maior contra a pirataria. 
Revista da Associação Nacional dos

Programas de Pós-Graduação em Comunicação

\section{e compós}

www.compos.org.b

A separação entre o cartão de abertura e as demais cenas do filme não pode ser apenas creditada ao estágio incipiente em que se encontrava a narrativa cinematográfica em 1903. Ela, principalmente, é fruto de uma limitação técnica dos processos de copiagem de filmes no início do século XX somado à uma percepção de custo e benefício. Não era prático sobrepor legendas às imagens previamente filmadas até o aperfeiçoamento e difusão de dispositivos conhecidos como trucas, bancos ópticos ou optical printers, o que aconteceria somente na década de 1920 (Rickitt, 2000, p.42).

Isto limitava consideravelmente as opções para a apresentação dos créditos. Ou eles estariam incorporados no cenário, como já vinha sendo feito desde o século XIX ou apresentados em cartões isolados, como o mostrado em O Grande Roubo do Trem.

Os créditos de abertura, invariavelmente apresentados ao início do filme, tinham esta função dupla: apresentar o título da obra e atribuir sua propriedade. Como a noção de estrelas em papéis de protagonismo era incipiente, estes nomes em geral não eram apresentados. Tampouco eram apresentados os nomes de membros da equipe exceto, em alguns casos, o produtor. Tal panorama se transforma ao longo da década de 1910 e, nos, primeiros anos da década de 1920, o conteúdo dos créditos de abertura já se aproximava de um padrão reconhecido pelas próximas décadas (incluindo empresa produtora, título, elenco principal e secundário, equipe e prólogos textuais). Sua forma, contudo, se adaptaria aos estilos gráficos de cada momento.

A apresentação visual dos créditos do cinema em seus primeiros anos buscava raízes nas artes de cartazes populares do final do século XIX, ainda que em uma apresentação simplificada pela falta de resolução, pelo alto contraste e pela ausência de cor da imagem cinematográfica em relação ao papel. Tais referências aos cartazes novecentistas envolviam o acréscimo de pequenos adereços à tipografia do título do filme, apresentada em destaque. Em uma cultura onde a noção de industrialização da produção gráfica ainda encontrava restrições técnicas, a produção de créditos de abertura envolvia na maioria dos casos algum desenho manual das palavras e adereços, posteriormente refotografado e editado junto ao filme. 


\section{Diálogos sem voz, mas com palavras}

Motivações narrativas para o surgimento das legendas, créditos e títulos em filmes começaram a aparecer na virada do século (figura 1). Em um filme chamado How it Feels to be Run Over $^{1}$ (Cecil Hepworth, 1900), um dos primeiros a incluir textos gráficos, as legendas que seguem ao atropelamento do cinegrafista apresentam a irônica frase "Mother will be pleased" ("Mamãe vai ficar contente”), mostrando os últimos pensamentos do cinegrafista em uma fonte manuscrita branca sobre fundo escuro.

Tais cartões funcionam basicamente como uma metáfora em forma e conteúdo do término da vida do personagem. O conteúdo das palavras e dos símbolos gráficos sugere a surpresa e ironia com o acontecimento trágico. A rapidez com que são apresentadas, apenas piscando na tela por uma fração de segundo, indica o esvanecer da consciência do sujeito. A fonte é manuscrita e irregular.

Não fica claro qual foi a maneira de registrar os cartões, mas, uma vez que as palavras e símbolos gráficos apenas piscam na tela, é bastante provável que tenham sido desenhados perfurando ou raspando a própria película.

\footnotetext{
${ }^{1}$ Em uma tradução livre, “Qual a sensação de ser atropelado”.
} 

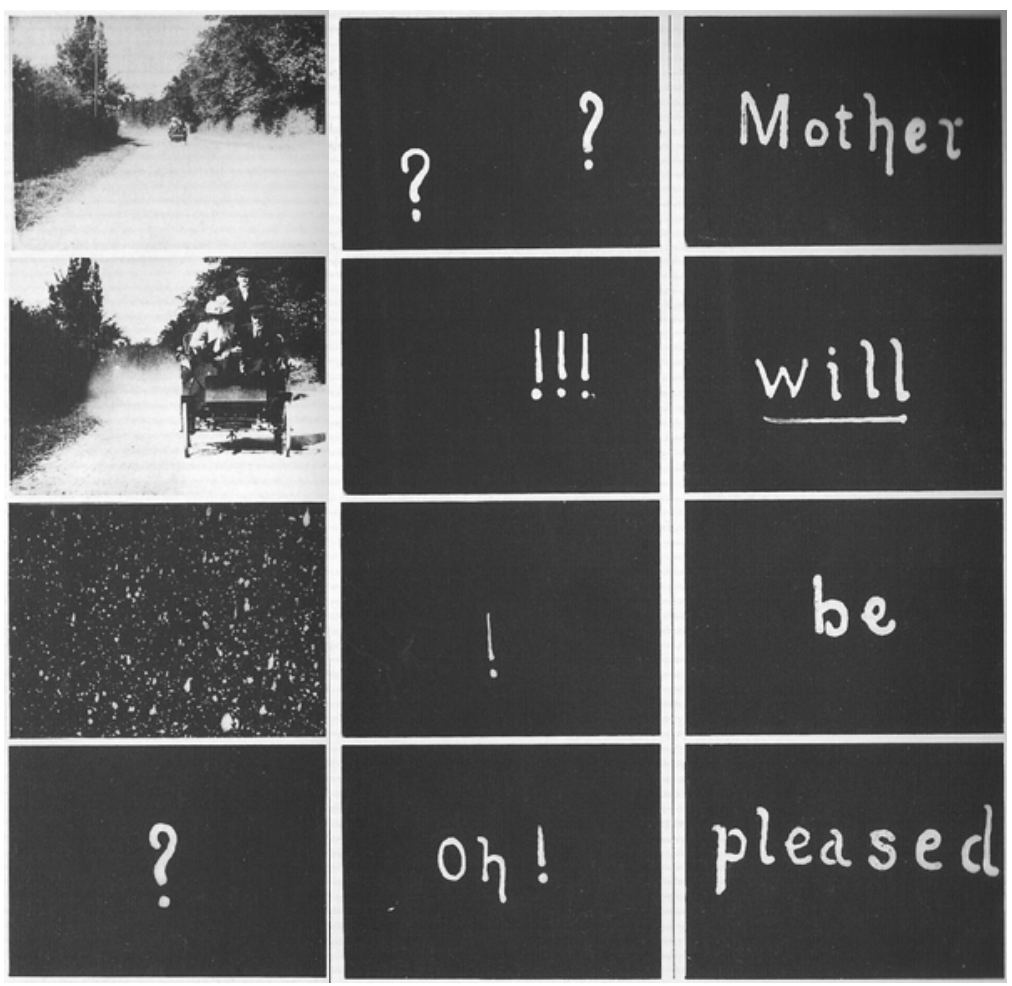

Figura 1 : Legendas de How it Feels to be Run Over (em TOULET,2000). Leia por colunas, da esquerda para a direita.

As forças que moviam a mescla entre conteúdos gráficos e cinematográficos, contudo, iam além das meras necessidades narrativas. O cinema em poucos anos se consolidou como uma arte industrial. E sua tendência à internacionalização da distribuição dos produtos acentuou ainda mais esta característica.

Antes de 1910 se estruturou uma indústria de distribuição que tinha escritórios em diversos países, em ambos os lados do Atlântico e em ambos hemisférios. Manter o suprimento de novos filmes para um mercado global em formação exigia a duplicação em grandes quantidades das obras, além de uma adaptação de legendas e créditos à variedade de línguas entre os países se a relação custo-benefício se mostrasse favorável.

A necessidade crescente de cópias dos filmes para atender os diferentes mercados exigia uma segmentação dos profissionais, como relata Usai (2000): 
Revista da Associação Nacional dos

Programas de Pós-Graduação em Comunicação

\section{(e) compós}

www.compos.org.b

Em média, uma comédia Keystone em 1914 era lançada com pouco mais de trinta cópias, embora quarenta cópias do filme de Chaplin Dough and Dynamite $^{2}$ e 41 de His Trysting [sic] Places ${ }^{3}$ foram impressas. Chaplin mesmo disse que 135 cópias de seu primeiro filme feito para a Essanay, His New Job ${ }^{4}$ (1915) já estavam agendadas previamente para exibição ao final da rodagem. Quando a Mutual lançou The Floorwalker ${ }^{5}$ de Chaplin em maio de 1916, setenta e cinco cópias foram necessárias somente para Nova Iorque [...] Em 1919 havia mais de 15000 salas de cinema nos Estados Unidos [...] (USAI, 2000, p.11)

O número de cinemas em 1919 é impressionante, ainda que seja necessário levar em conta que absolutamente qualquer lugar poderia se tornar um cinema. De tendas em exposições, apartamentos com as paredes derrubadas ou salas alugadas. Prédios construídos especialmente ou salas de vaudeville. Com certeza os freqüentadores do início do século XX ainda não iam a salas de cinema multiplex, um conceito que somente se consolidou na década de 1970 (Gomery in Cook, 2002, p.397).

Dadas as limitações técnicas da copiagem de filmes no início do século XX, não raro o mesmo filme era rodado com duas câmeras simultaneamente lado a lado. Um negativo seguia para o mercado doméstico e o outro serviria de matriz para as cópias do mercado internacional, reduzindo o desgaste de ambas (Usai, 2000, p.120). Em termos de tipografia, de comunicação gráfica, a atenção era mínima. Limitava-se à estrita objetividade com um mínimo de complementos.

A criação e execução de créditos e intertítulos para os filmes estava próxima da realização de anúncios e demais materiais gráficos de publicidade. Um cartão de título monocromático em alto contraste é, essencialmente, similar a um fotolito, base da produção gráfica publicitária. Passar de uma área (impressos publicitários) à outra (créditos) era tecnicamente e criativamente menos complexo que para outras áreas de

\footnotetext{
${ }^{2}$ Em tradução livre, "Rosquinha e Dinamite”.

${ }^{3}$ Livremente traduzido, "Seus Locais de Bebericar".

${ }^{4}$ Livremente traduzindo, "Seu Novo Emprego".

${ }^{5}$ Em uma tradução livre, "O pé-de-valsa”.
} 
Revista da Associação Nacional dos

Programas de Pós-Graduação em Comunicação

\section{(e) compós}

www.compos.org.br

conhecimentos bastante específicos da realização cinematográfica, como a direção de fotografia ou a montagem.

Durante os anos em que o cinema mudo consolidou a forma de contar as histórias também foram os anos da juventude de Alfred Hitchcock, um diretor conhecido amplamente por sua obra junto a filmes de suspense, crimes e espionagem. Então um jovem ilustrador formado em uma escola técnica, Hitchcock apresentou seus desenhos e anúncios para uma subsidiária da Paramount no início da década de 1920 em Londres e iniciou em um emprego como ilustrador de intertítulos ${ }^{6}$.

F.T. Por 'títulos' você quer dizer as legendas que representavam o diálogo em filmes mudos?

A.H. Certo. Naquele tempo, os títulos eram ilustrados. Cada cartão tinha o título narrativo, o diálogo e um pequeno desenho. O mais famoso destes títulos narrativos era 'E veio o amanhecer'. Você também tinha 'Na próxima manhã...' Por exemplo, se o texto dissesse ‘George estava levando uma vida muito agitada naquele tempo’, eu desenharia uma vela acesa nas duas pontas, bem abaixo da frase. Muito ingênuo. (TRUFFAUT \& SCOTT, 1983, p. 27)

O senso crítico de Hitchcock já trata de anexar ao relato seu próprio juízo de valor a respeito da estética dos intertítulos. A ingenuidade da representação gráfica junto da legenda verbal lembra as ambições de estabelecer uma comunicação direta e sem ambigüidades. De qualquer maneira, a possibilidade de variação na conotação dos gráficos nos cartões de título parecia ser pequena. Estando inseridos dentro da obra maior (o filme) como acessórios, qualquer significante que sugerisse algo diferente aos temas da obra seria facilmente esquecido ou lido como meramente decorativo. Os conjunto de

\footnotetext{
${ }^{6}$ Ainda que uma designação mais sintonizada com as atividades publicitárias contemporâneas fosse diretor de arte, escolhi evitar o termo para não confundir as coisas com a atividade principal de Hitchcock alguns anos mais tarde.
} 
Revista da Associação Nacional dos

Programas de Pós-Graduação em Comunicação

\section{e compós}

www.compos.org.br

signos do filme quando não ancorado pelo conteúdo verbal eram essencialmente polissêmicos em sua leitura, como Hitchcock afirma com humor:

[...] Mais tarde eu me tornei chefe do departamento de títulos. Fui trabalhar no departamento de roteiros do estúdio. O chefe do departamento tinha dois roteiristas americanos sob seu comando e quando um filme estava concluído, o chefe do departamento de roteiros iria escrever os cartões de título ou reescrever aqueles do script original. Porque, naqueles tempos, era possível mudar completamente o sentido de um roteiro através do uso de títulos narartivos e de fala.

\section{F.T. Como?}

A.H. bom, como o ator fazia de conta que falava e o diálogo aparecia na tela logo depois, eles podiam colocar quaisquer palavras gostassem na boca dele. Muitos filmes ruins foram salvos assim. Por exemplo, se um drama tivesse sido mal filmado e fosse ridículo, iriam inserir títulos de comédia em todo o filme e ele se tornaria um sucesso. Porque, você vê, virava uma sátira. O sujeito podia fazer realmente tudo - pegar o final do filme e botar no início - tudo mesmo! (TRUFFAUT \& SCOTT, 1983, p. 27)

Relativizando os comentários de Sir Alfred a partir do que afirma Musser (1994, p.2) podemos afirmar com segurança que se esta reordenação dos conteúdos podia ser feita com uma simples interferência na montagem e nos cartões de fala, ela também reflete as limitadas cobranças das platéias da época com relação à sofisticação do espetáculo ou com a continuidade.

Apesar da consolidação das legendas, a essência do cinema mudo permanece a imagem em movimento. Por exemplo, na seqüência do assassinato do presidente Lincoln em $\mathrm{O}$ Nascimento de Uma Nação (D.W. Griffith, 1915) da chegada do presidente ao teatro à fuga de John Booth há 39 planos e 7 cartões de título, apenas um representando uma fala 
Revista da Associação Nacional dos

Programas de Pós-Graduação em Comunicação

\section{(e) compós}

www.compos.org.b

(Reisz \& Millar, 1968). A compreensão do que a cena representa (o presidente dos EUA é assassinado por John Booth em um teatro) acontece sem problemas para espectadores minimamente familiarizados com os códigos de leitura de um filme e com os acontecimentos históricos.

Os recursos narrativos que Griffith consolidou no cinema (montagem paralela de ações, enquadramento usado como ênfase dramática, atuações se afastando da pantomima, ênfase em ações externas e não introspectivas) formaram a base da estrutura do classicismo cinematográfico. Os intertítulos com falas e esclarecimentos a respeito das situações mostradas na tela se tornaram necessários para ancorar a conotação uma vez que a duração dos filmes se ampliou e suas tramas se tornaram mais complexas, mas apenas como uma medida intermediária dada a inviabilidade de apresentar som em sincronia com a imagem de maneira confiável e economicamente viável.

A descontinuidade criada pelo entrecortar entre as seqüências rodadas com elenco e os cartões ancorava as conotações, mas também prejudicava o envolvimento do espectador com a obra uma vez que rompia a cada pouco a relação indicial e icônica que o visual do filme estabelece com o espectador, conduzindo-o para uma relação verbal simbólica e arbitrária e trazendo-o de volta segundos depois. Ainda que a competência de leitura dos espectadores fosse capaz de superar esta variação, o cinema carecia de uma maneira de envolver o espectador completamente, sem aparas.

\section{Considerações finais}

A mescla entre comunicação gráfica e imagens cinematográficas está presente desde os primeiros momentos do cinema, atendendo a uma variedade de formas e propósitos. Isto insere o então nascente cinema em uma continuidade com as linguagens já existentes, ainda que destacado amplamente das demais por sua capacidade de mimetizar o efêmero e o movimento, sugerindo uma mediação da imagem com o que representa. 
Revista da Associação Nacional dos

Programas de Pós-Graduação em Comunicação

\section{(e) compós}

www.compos.org.b

A inserção de frases, palavras e símbolos gráficos sobre a imagem, na imagem e entre as imagens mostradas no cinema mostra desde o princípio que o meio é capaz de transcender a mera mímese e estruturar-se de maneira mais complexa, comunicando mensagens mais elaboradas.

Sua estratificação em diferentes soluções lançou as bases para as convenções contemporâneas de como conteúdos tipográficos devem se mesclar às imagens. Legendas, por exemplo, continuam a cumprir o papel dos intertítulos do cinema dos primeiros anos, agora podendo aparecer sem interromper o andamento do filme por serem sobrepostas à imagem. Logotipos -a primeira mescla- continuam a ser colocados nos cenários e ter sua aparição vinculada a ações de merchandising e marketing vendendo produtos relacionados à história em obras de um cinema pensado como indústria primeiro e depois como arte. Créditos se sofisticaram graficamente da década de 1950 em diante, passando por períodos de maior destaque ou de menor sofisticação.

Com a estabilização da linguagem cinematográfica clássica com a difusão do som sincronizado na década de 1930, os elementos gráficos se tornaram progressivamente secundários nos filmes. Suas formas se adaptaram, porém as necessidades de comunicação e ancoragem permanecem existindo na produção audiovisual.

\section{Referências bibliográficas}

BAZIN, André. The Evolution Of The Language Of Cinema in BRAUDY, Leo \& COHEN, marshall (eds.). Film Theory and Criticism - Introductory Readings (fifth edition). Nova Iorque. Oxford University Press, 1999.

BARTHES, Roland. L'Aventure Semiologique. Paris : Editions du Seuil, 1985.

BOGDANOVICH, Peter. Afinal quem faz os filmes. São Paulo : Companhia das Letras, 2000. CARRIÈRE, Jean-Claude. A Linguagem Secreta do Cinema. São Paulo : Nova Fronteira, 1995. GOMERY, David. Motion Picture exibition in 1970s America in COOK, David. A. (ed.). Lost Illusions: American Cinema in the Shadow of Watergate and Vietnam 1970-1979. Los Angeles : California University Press, 2002.

FISKE, J. (et al). Key Concepts in Communication. London : Methuen, 1983.

FONSECA, Joaquim da. Caricatura: a Linguagem Gráfica do Humor. Porto Alegre : Artes e Ofícios, 1999. 
Revista da Associação Nacional dos

Programas de Pós-Graduação em Comunicação

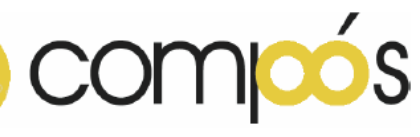

www.compos.org.br

MANNONI, Laurent. A Grande Arte da Luz e da Sombra. São Paulo: Editora Senac \& Editora UNESP, 2003,

MEGGS, Philip. A History of Graphic Design. Nova Iorque: Van Nostrand Reinhold, 1995.

MUSSER, Charles. The Emergence of Cinema: The American Screen to 1907. Los Angeles :

California University Press, 1994.

REISZ, Karel \& MILLAR, Gavin. Technique of Film Editing. Nova Iorque : Focal Press, 1968.

RICKITT, Richard. Special Effects, the history and the technique. Nova Iorque : Billboard Books, 2000

SCOTT, Helen G. ; TRUFFAUT, François. HITCHCOCK (REVISED EDITION). Nova Iorque : Touchstone Books, 1985.

TOULET, Emmanuelle. O cinema, invenção do século. São Paulo: Objetiva, 1999

TWYMAN, Michael. The Graphic Presentation of Language. In Design Jounal, Vol 3/1.1982.

USAI, Paolo Cherchi. Silent Cinema: An Introduction (Distributed for the British Film

Institute). Londres : British Film Institute, 2000. 